\title{
Numerical approach regarding functional and design optimization for a residential building daily hot water system composed by heat pump and auxiliary source
}

\author{
Mugurel Florin Talpiga ${ }^{1, *}$,Eugen Mandric ${ }^{1}$, and Florin Iordache $^{1}$ \\ ${ }^{1}$ Faculty of Building Services, Technical University of Civil Engineering of Bucharest, Bucharest, Romania
}

\begin{abstract}
In this paper is presented the physical model and mathematical approach which describe the equation system used in system calibration and design optimization. The system proposed for study is built from heat pump, for energy demand delivery, together with auxiliary heating source to face in all low temperature days, when heat pump work at maximum load but the required demand for daily hot water by the building inhabitants is higher. The paper present few of the common used systems in market for which the mathematical equation system will be proposed to come in help designers for in simulation and cost optimization. Simulation of proposed design is realized and results are delivered. The system construction, is optimized by comparison study of design and simulation data for each system type proposed. The comparison study is used for cost estimation of system and energy balance.
\end{abstract}

\section{Introduction}

Daily hot water for building sector, residential and commercial, is in all cases a demand to respect in design. Methodologies to evaluate daily heating water demand (DHW) [1] and optimisation techniques [2] exist today for various user profiles and with more interest in energy efficient buildings with focused on nearly zero energy consumption [3]. Optimisation techniques for designing and equipment selection purpose, is in general based on heating demand and dynamic modelling of real functioning with specific tools. In research area, hybrid systems were mathematically modelled for multi objective optimisation [4].

Decreasing of fossil fuels dependency based on renewables technology is encouraged today. A $10.3 \%$ of total heat used for heating and cooling demand, is registered in 2016 as being from renewable sources [5]. Hybrid technologies is a mix of different types of equipment used together to provide, with an added value, the same quantitative output, at a required level of quality, or the same with equipment tacked separately. Hybrid systems for DHW are developed today in a wide range of mixed technologies. Phase change materials, to use latent heat temperature, as technology main advantage, for efficiency increasing objective were investigated [6-9]. Refrigerant absorption heat pumps is a key equipment in hybrid systems for DHW production [10-13], with his capacity to use the heat from another environment and store it, ore deliver it, at other temperatures, to be used in heating of the water. Over passed years of deep research and technology development, in terms of heat pumps controllers, multiple types of hybrid system topologies were developed. Based on availability in market and price decrease per equipment, multiple types of technology mixing is possible. Heat pumps with phase change materials for heat storage, in multiple configuration, are developed [14-17]. Phase change materials are generally used for their latent heat properties, based on the mixture of substances, the heat absorbed/released, until phase is changed, is made at a constant temperature. This property is useful in heat-pump configuration, when coefficient of performance (COP) basically being a temperature dependence indicator. Overall, PCMs help in energy reduction for water heating demands.

Air source heat pumps (ASHPs) are generally a selected solution in different type of heating/cooling applications. Due to their capacity to use the heat extracted from the air, is generally a good solution in all types of environments. Different types of ASHP are available $\mathrm{n}$ market. In cold environment, for heating, or in cold season for daily hot water, two types of systems are possible. Frost free equipment, which use an air ventilated evaporator, is generally tacked into control to not reach ice, and decrease air moisture condensation on the equipment [18]. At atmospheric pressure, air moisture condensate near temperature of $0^{\circ} \mathrm{C}$, his latent heat being transfer at this level, ASHP overall performances being, at evaporator, at a higher level. Different frosting conditions is a key behaviour of ASHP for distinct levels of performances can be registered [19].

Water source heat pumps (WSHPs) are generally characterised by the water source to extract the heat from. River water is one of the multiple WSHPs types. Optimisation for this type of WSHP in configuration with a combined cooling, heating and power system

* Corresponding author: talpiga.mugurel@gmail.com 
were done by [20], study which reveal the overall performances. Underground water source heat pump [21] is studied to investigate energy efficiency and performance level by comparison of two different types of underground WSHPs.

A big influence in energy consumption, consist in user profile. User profiles are generally characterised by hot water flow rate and hot water temperature. Standardisation over the countries tried to establish a convenient methodology, in terms of normative, to be used in equipment selection and system design. Types of application conduct to different user profiles, residential and hotels have different user profiles; a brief revue were lunched and reveal a wide range of user hot water volume demand for different hot water delivery temperature [22]. In this study, for residential buildings, volume per occupant vary from $30 \mathrm{l} /$ day, in Spain, to 94 1/day in Canada. As general conclusion of mentioned paper, demand profiles are far to exist in a generic helpful form today, to be used by designers in hot water systems evaluation. A wide range of flow rates and temperature profiles influence in equipment selection analyse, is today a necessary action to lunch. Temperature used for hot water demand it also vary from designer to designer, in literature a wide interval of temperatures are used starting from $45^{\circ} \mathrm{C}$ until $65^{\circ} \mathrm{C}$. A brief analyse make the object of optimisation regarding equipment used in hot water preparation.

In hot water preparation equipment, a common risk is related to Legionella apparition and a good control of bacteria inside the system is the most important goal. Research reveal a proper control of Legionella apparition is done when hot water temperature is at least $55^{\circ} \mathrm{C}$ with a minimum acceptance value of $50^{\circ} \mathrm{C}$ [23]. This conclusion was obtained over a statistical analyse over a period of 8 years.

For the evaporator, outside temperature will conduct the behaviour of equipment in case of ASHP. Knowing air temperature, with the methodology proposed in this paper, can be energetically evaluated a certain system for a certain user. Outside temperature data should be available to be able to perform system simulation. One of the common databases is Meteonorm, were external temperatures and other important weather parameters can be found.

Water source temperature, in case of a WSHP, is giving the evaporator environment working conditions, in case of heating. Temperatures between $11.5^{\circ} \mathrm{C}$ and $13^{\circ} \mathrm{C}$ were used for simulation $n$ case of a ground water source heat pump located in Zhangye area, of Nord China, with stable temperature values over a variable outside temperatures [24]. In heating season, for a South area of China, lake water temperature values registered, were in interval of $5^{\circ} \mathrm{C}$ to $10^{\circ} \mathrm{C}$, in case of lake water source [25].

Electrical power of compressor is a user profile dependant and also, for purposed models to be study, an energy ratio between heat pump energy delivered and total energy demand. Different user hot water volume demand and different energy ratio will be varied to establish the proper value of electrical power for the compressor. Also, for a real optimisation the temperatures of external air and water source will be varied to establish the interdependency of them and energy ratio.

\section{Mathematical model}

Water source heat pump considered for modelling, is based on relative quasi-constant temperature of underground or surface lakes water. Heat pump extract the heat from the water using different types of equipment such heat-exchangers or indirect immersed evaporators with respect of refrigerant pressure for unfreezing purpose. A schematic of the system configuration, for building heating demands, and water source based on lake water is presented in Figure 1.

The system considered take into account the all elements, from the heat source to delivery plugs of the heating agent. The building is generally presented to reveal the internal design temperature set point.

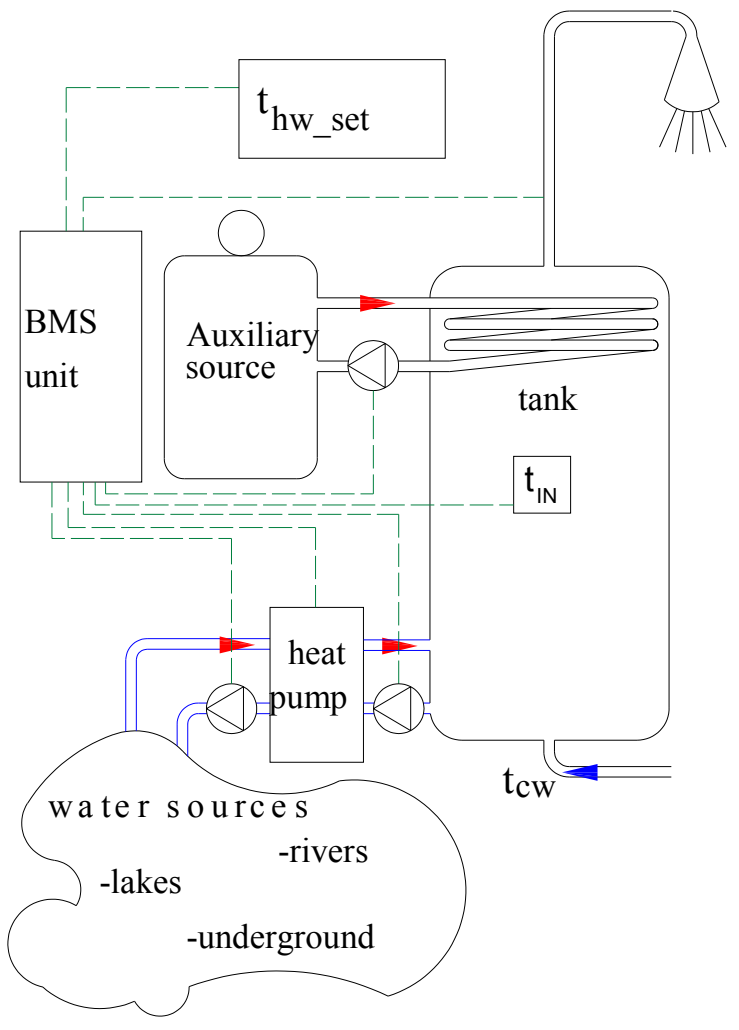

Fig. 1. WSHP system model considered.

Condensation temperature is considered the value in the middle interval, between cold water temperature and hot water delivered temperature [1]. The expression of this temperature is found in equation (1) and is referring to both, design temperatures, hot water respectively input cold water to be heated up.

$$
\theta_{C D}=t_{C W}+0.5 \cdot\left(t_{H W}-t_{C W}\right)
$$

Heat pumps working parameters are based on evaporator and condenser powers, together with electrical power of refrigerant compressor. Those 3 coefficients give the coefficient of performance (COP) 
of the systems in cooling or heating season, depending of interest. Because this paper will present a methodology for DHW preparation, the condenser will always heat the tank, COP in this case being a heating COP expressed by condenser power and electrical power. COP can also be driven by Carnot cycle, being a rapport of condenser temperature over temperature difference between condenser and evaporator [2]. Therefore, condenser power can be expressed as electrical power, condenser temperature and evaporator temperature dependant. This statement is observed in equation (2).

$$
\mathbf{Q}_{\mathbf{C D}}=\eta_{i s} \cdot W_{E L} \cdot\left(\theta_{C D}+\Delta_{C D}+273.15\right) /\left(\theta_{C D}-\boldsymbol{\theta} \mathbf{V P}+\Delta_{C D}+\Delta_{V P}\right)
$$

In this equation, isentropic efficiency is taking into consideration due to Carnot real cycle efficiency. Condenser and evaporator temperatures are always higher, respectively lower comparing environment where installed to be able to give, respectively extract the heat. With a specific temperature differences at evaporator, condenser power can be evaluated accordingly. In heat exchangers, used to transfer the heat from evaporator environment to refrigerant and respectively to transfer the heat from refrigerant to the condenser environment, the pinch temperature difference is evaluated in literature to minimise the irreversibility with entropy analyse of equipment, for specific refrigerant statement [26-29]. For various mass flow rates, pinch point temperature difference, or temperature difference between refrigerant and liquid, registered values for various length of the condenser, were situated inside interval of $4^{\circ} \mathrm{C}-7^{\circ} \mathrm{C}$ [28].

Heating demand for DHW consist in a specific daily hot water volume, generally expressed as a specific occupant volume, by normative selection, multiplied by number of occupants and described in equation (3).

$$
\mathbf{Q}_{\text {LOAD_day }}=\mathbf{G}_{\mathbf{S P}} \cdot \rho_{W} \cdot c_{W} \cdot \mathbf{N}_{\text {ocupants }}
$$

Water volume heating demand is based on water density and specific heat, denoted $\rho_{\mathrm{W}}$ and $\mathrm{c}_{\mathrm{W}}$ inside equation (3) and specific water flow rate per day, Gsp. It was selected a specific flow rate because the methodology will use yearly evaluation and flow rate is generally a daily consumption flow rate. Electrical power of the compressor will be evaluated as a function of daily heating demand, at the end of this paper a proper coefficient will be proposed, to satisfy a certain demand. The evaluation consist in usage of an electrical factor, which represent the percentage of electrical power from the total DHW load and expressed by equation (4).

$$
\mathbf{W}_{\mathbf{E L}}=f_{D H W} \cdot \mathbf{Q L O A D}_{\mathbf{d a y}}
$$

Electrical factor, $\mathrm{f}_{\mathrm{DHW}}$, is a key parameter when a certain system is selected to deliver the heat for DHW demand. Having this in hand, will be known the compressor power as a minimum value, for the selected schematic of heating system, to satisfy an energy ratio between energy delivered by the heat pump and total energy required for DHW.

For an entire year, air temperature in different environments have values variation from positive to negative values, in continentally-tempered weathers.
Those values will generally affect the performances of systems like this paper proposed. The evaluation of performances will be done here, by total energy analyse over the year and reported to both, auxiliary source or heat pump, in case of ASHP. Regarding WSHP, for underground water the temperatures are generally stable over the year. In equation (5), both ASHP and WSHP equations for heating power provided by heat pumps are presented.

$$
\begin{aligned}
& \mathbf{Q}_{\mathbf{A S H P}}=\eta_{i s} \cdot W_{E L} \cdot\left(\theta_{C D}+\Delta_{C D}+273.15\right) /\left(\theta_{C D}-\mathbf{t}_{\mathbf{e}}+\Delta_{C D}+\Delta_{V P}\right) \\
& \mathbf{Q}_{\mathbf{W S H P}}=\eta_{i s} \cdot W_{E L}\left(\theta_{C D}+\Delta_{C D}+273.15\right) /\left(\theta_{C D}-t_{C W}+\Delta_{C D}+\Delta_{V P}\right)
\end{aligned}
$$

External temperature over the year will affect overall heating power provided by first relation from equation (5). Q ASHP represent the power at output plugs of the heat pump, or condenser power of the ASHP. This relation have the base COP Carnot, for which the condenser and evaporator temperatures of refrigerant states will generate the overall performances of the equipment. According Figure 2, heat pump will extract the heat from the air and will discharged it to the tank using a circulating pump which transport the agent from the tanks to heat pump heat exchanger.

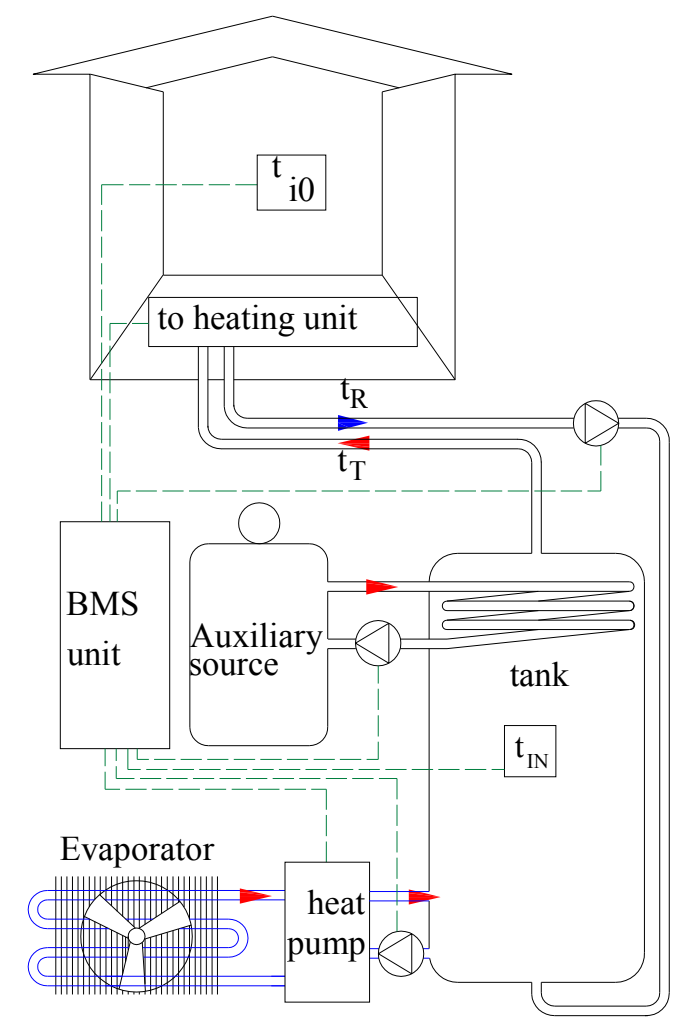

Fig. 2. ASHP system model considered.

The pinch temperature for the exchanger will give the values of temperature difference at evaporator and condenser, $\Delta_{\mathrm{VP}}$, respectively $\Delta_{\mathrm{CD}}$. Values variation, for simulation, are used in equation (2) to evaluate the behaviour of the overall heating power when different system parameters are varied, like compressor efficiency, electrical factor, hot water temperatures. Obtained necessary load, QLOAD_day, compared with 
QASHP and AwshP, from equation (5), will reveal the mismatch of condenser powers for certain parameters values and the minimum parameters values to satisfy condition.

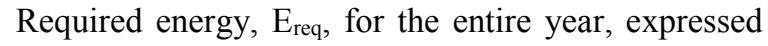
in $\mathrm{kWh}$ is it easily evaluated through equation (6). For all years of the day, the heating load for hot water production is considered constant for this paper, taking into consideration only the specific occupant volume, parameter also varied to establish a certain optimisation.

$$
\mathbf{E}_{\text {req }}=365 \cdot \mathbf{Q L O A D}_{\text {day }} 2410^{-3}
$$

Energies, $E_{\mathrm{ASHP}}$ and $\mathrm{E}_{\mathrm{WSHP}}$, from the heat pump condensers, will give the possibility to evaluate total energy obtained from heat pumps using equation (7) for the entire year, expressed in $\mathrm{kWh}$.

$$
\begin{aligned}
& \mathbf{E}_{\mathrm{ASHP}}=365 \cdot \mathbf{Q}_{\mathrm{ASHP}} 2410^{-3} \\
& \mathbf{E}_{\mathrm{WSHP}}=365 \cdot \mathbf{Q}_{\mathbf{W S H P}} 2410^{-3}
\end{aligned}
$$

Electrical energy consumed by the heat pump, EELASHP $_{\text {EL }}$ and EL_WSHP, can be evaluated over the year using equation (8).

$$
\begin{aligned}
& \mathbf{E E L}_{-} \text {ASHP }=365 \cdot \mathbf{W}_{\text {EL_ASHP }} 2410^{-3} \\
& \mathbf{E}_{\text {EL_WSHP }}=365 \cdot \mathbf{W}_{\text {EL_WSHP }} 2410^{-3}
\end{aligned}
$$

Difference between total delivered energy of heat pump and electrical energy, will return the renewable energy delivered to system. Reporting this to total energy demand, by equation (9), will be obtained the renewable energy percent, or renewable energy ratio from the total hot water energy demand.

$$
\begin{aligned}
\text { RREN_ASHP } & =\left(\mathbf{E}_{\text {ASHP }}-\mathbf{E E L}_{-} \text {ASHP }\right) / \mathbf{E}_{\text {req }} \\
\text { RREN_WSHP } & =\left(\mathbf{E}_{\text {WSHP }}-\mathbf{E E L}_{-} \text {WSHP }\right) / \mathbf{E}_{\text {req }}
\end{aligned}
$$

Global energy ratios, $\mathrm{G}_{\text {ER_WSHP }}$ and $\mathrm{G}_{\text {ER_ASHP, }}$ between heat pump delivered energy and total energy load, over the year, is a useful indicator, to show how much energy is delivered by the heat pump from the total load and expressed by equation (10).

$$
\begin{aligned}
& \mathbf{G}_{\text {EN_ASHP }}=\mathbf{E}_{\text {ASHP }} / \mathbf{E}_{\text {req }} \\
& \text { GEN_WSHP }=\mathbf{E} \text { WSHP } / \mathbf{E}_{\text {req }}
\end{aligned}
$$

Auxiliary source energy demand is the remaining energy to be delivered to reach the total energy demanded by system. This system is not evaluated for performances. His internal efficiency will give the overall energy required to satisfy the auxiliary energy for hot water demand.

\section{Simulation results}

Presented evaluation methodology for system optimisation purposes and energy balance, between renewable energy and energy required to deliver the entre volume of hot water, present a set of advantages regarding complexity of the method and data required to obtain final results. Generally, for thermal energy simulations, are used weather data obtained by different technics from registered values over the year [30].

First interest parameter is electrical factor to be able to see the electrical power required for heat pump compressor. In Figure 3, for a compressor with isentropic efficiency 0.6 , condenser power is plotted. DHW power corresponding to the graph of Figure. 3 is $4.51 \mathrm{~kW}$, necessary power to heat up 701 of water from 10 to $65^{\circ} \mathrm{C}$.

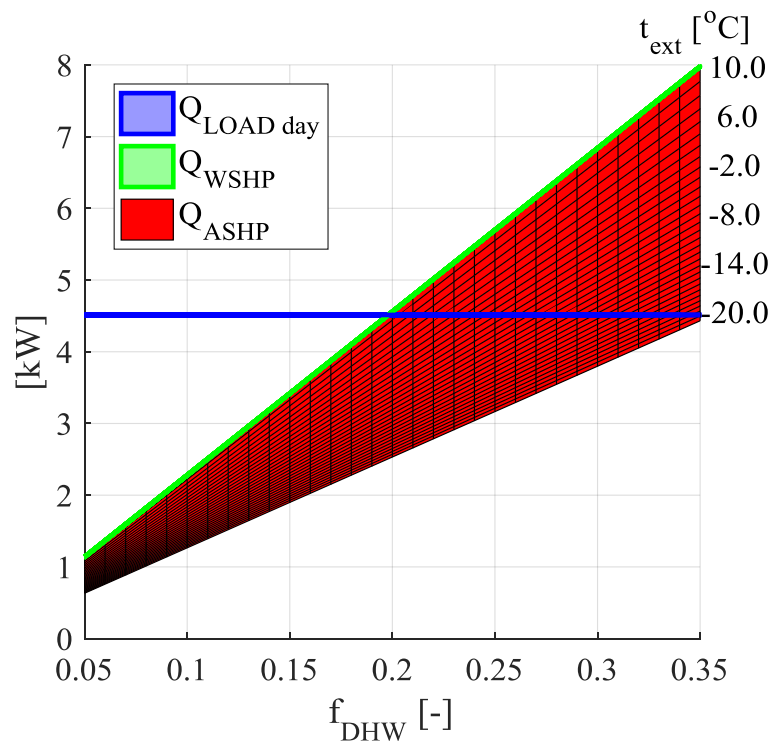

Fig. 3. DHW demand and water to water, respectively air to water heat pump condensers power, when external temperature and fDHw are input variables

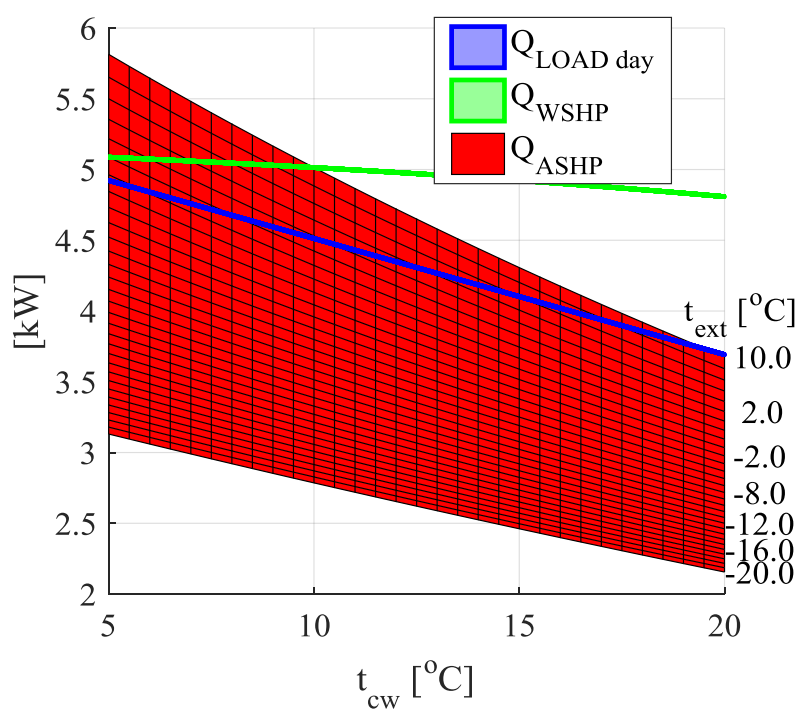

Fig. 4. DHW demand and water to water, respectively air to water heat pump condensers power, when external temperature and hot water set point are input variables.

In Figure 4 is plotted the equipment power together with required load to heat up the same 701 of water volume, from different cold water temperatures until $65^{\circ} \mathrm{C}$, the value considered for hot water set point 
Set point is also a necessary condition when system design is tacked into account, for variation of external condition, required power for hot water production and heat pump delivered power, Figure 5 is showing the required values to satisfy the equality condition between powers. For this graph, corresponding values of water volume is 701 and $10^{\circ} \mathrm{C}$ input water temperature.

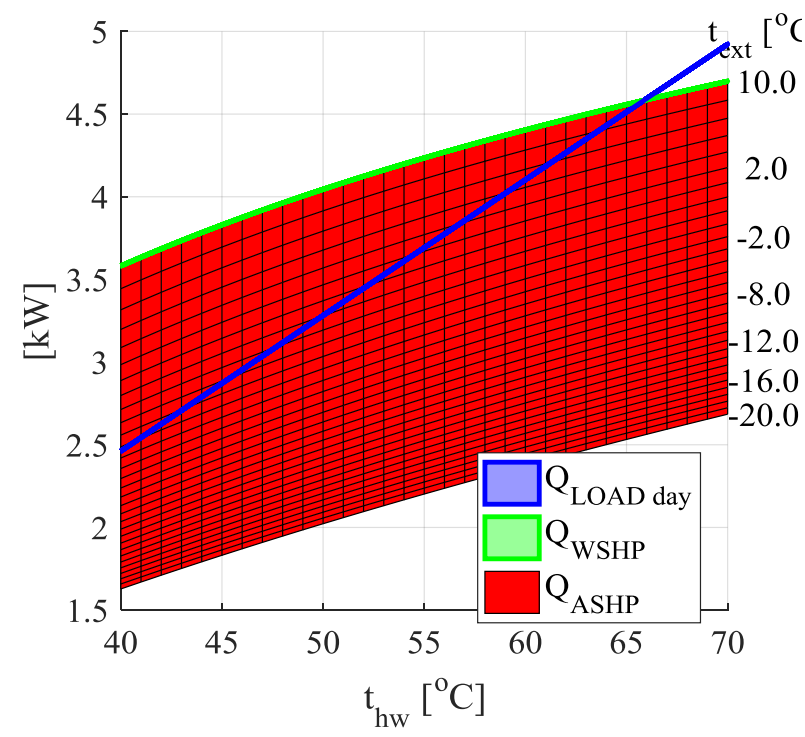

Fig. 5. DHW demand and water to water, respectively air to water heat pump condensers power, when external temperature and hot water temperature are input variables

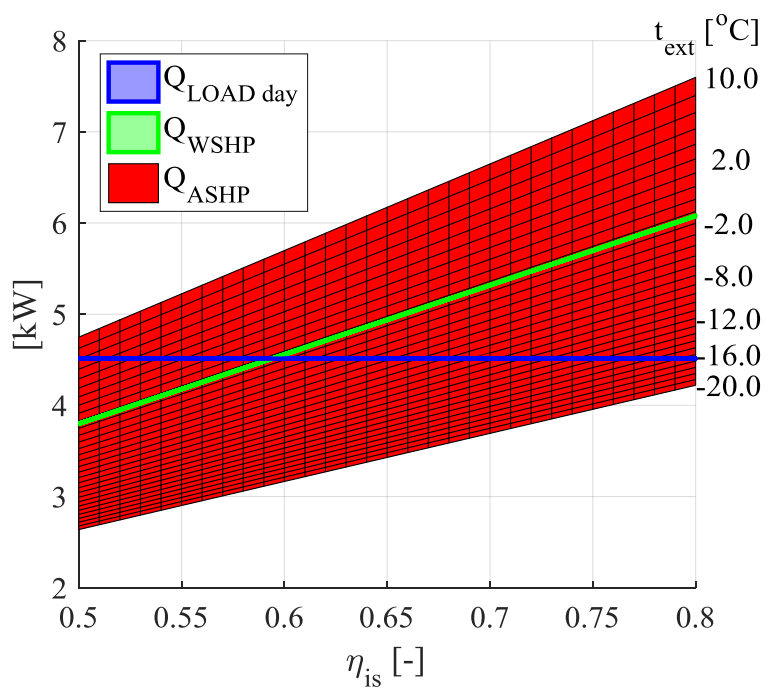

Fig. 6. DHW demand and water to water, respectively air to water heat pump condensers power, when external temperature and isentropic efficiency are input variables

In Figure 6 required power is plotted together with both condenser power when parameters compressor efficiency and external temperatures are varied. For $10^{\circ} \mathrm{C}$ input water temperature and 701 water volume to be heated from $10^{\circ} \mathrm{C}$ to $65^{\circ} \mathrm{C}$, Figure 6 show the values of each varied parameters, to satisfy the equality conditions between required and delivered power at heat pumps condensers. For this graph, temperature difference at evaporator and condenser side is equal to $5^{\circ} \mathrm{C}$, difference needed for transfer the heat from the evaporator environment o refrigerant respectively, at condenser, from the refrigerant to the water.

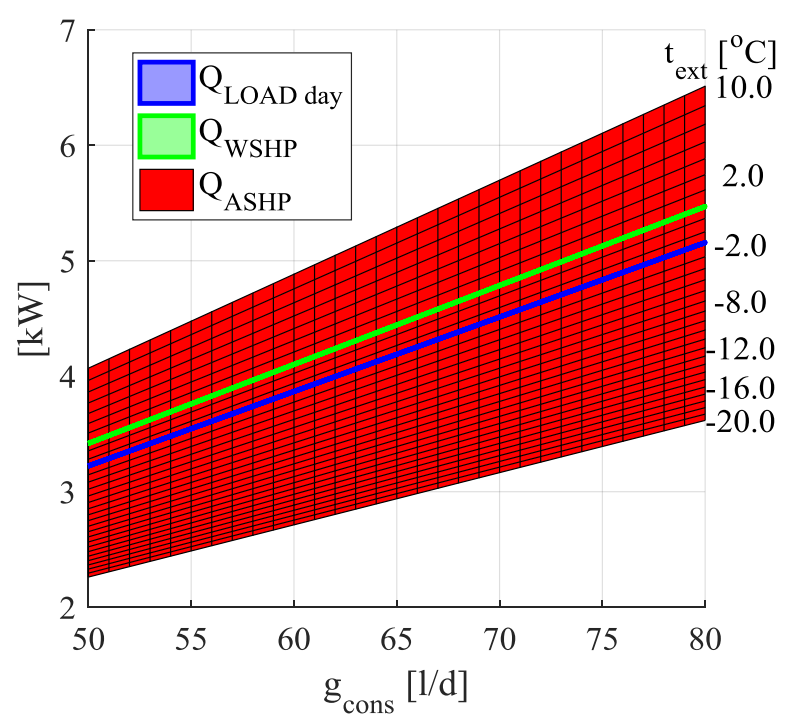

Fig. 7. DHW demand and water to water, respectively air to water heat pump condensers power, when external temperature and daily specific flowrate are input variables

Required power to heat up the water in a system with a specific set-point temperature, depends generally by water volume. For different specific water flow per occupant, Figure 7 reveal the conditions to satisfy the required load. For the same temperature differences, equal to $5^{\circ} \mathrm{C}$ for evaporator and condenser, and hot water temperature set point equal to $65^{\circ} \mathrm{C}$, in case of ASHP, only for temperatures over $-2^{\circ} \mathrm{C}$, heat pump can deliver the required power. In those conditions, for temperatures below $-2^{\circ} \mathrm{C}$, auxiliary source should delivered the remaining heat to satisfy the occupant demand.

\section{Case study}

For system proposed, WSHP performances depends on 3 main parameters, hot water temperature set point, cold water temperature and user hot water flow rate. All the other parameters are internally designed by heat pumps and are manufacturer based knowhow, selected for the right working parameters. The environment parameters dependence is based on cold water temperature and hot water temperature set-point. A selection of pumps, based on actual methodology can be done, to satisfy the required heating for $\mathrm{DHW}$ production.

For ASHP, working performances are in direct link with air temperature, which for this study, is based on external temperature variation. To establish the performances, 5 cities from Romania are selected. External average daily temperatures, are obtained from Meteonorm database. Based on external temperature, and electrical factor selection, pump will deliver an amount of energy required by the system to prepare DWH and corresponding renewable energy ratio, based on heat extracted by heat-pump, at evaporator, from the 
external air, ratio evaluated by equation (9). The ASHP heat pump is designed to deliver the required heating for DHW in a certain external condition. For the external temperature, for which ASHP is designed, heat pump can sustain the total heat demand. Over this temperatures, heat pump can deliver more than required heating, but, by electrical power variation at compressor inlet, at condenser will be available only the necessary heat.

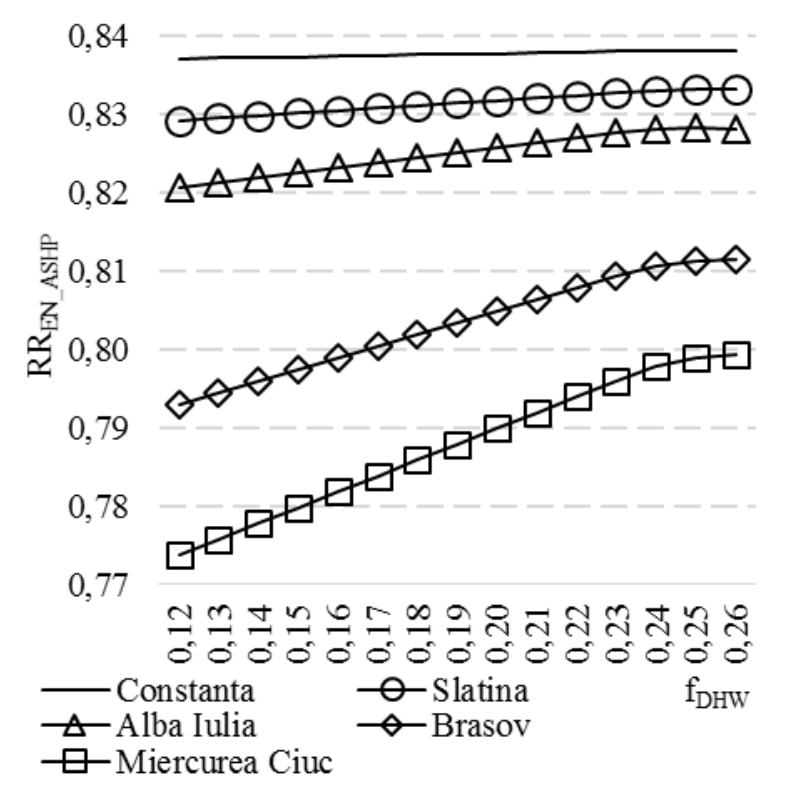

Fig. 8. Renewable energy ratio for 5 cities of Romania, when different electrical factor, $\mathrm{f}_{\mathrm{DHW}}$, is considered

For different electrical factor, energy delivered by heat pump changes accordingly. Due to the fact that renewable energy ratio is a heat pump electrical power dependent parameter, in Figure 8 can be seen how this parameter is varied over a range of 0.12 to 0.26 from electrical factor.

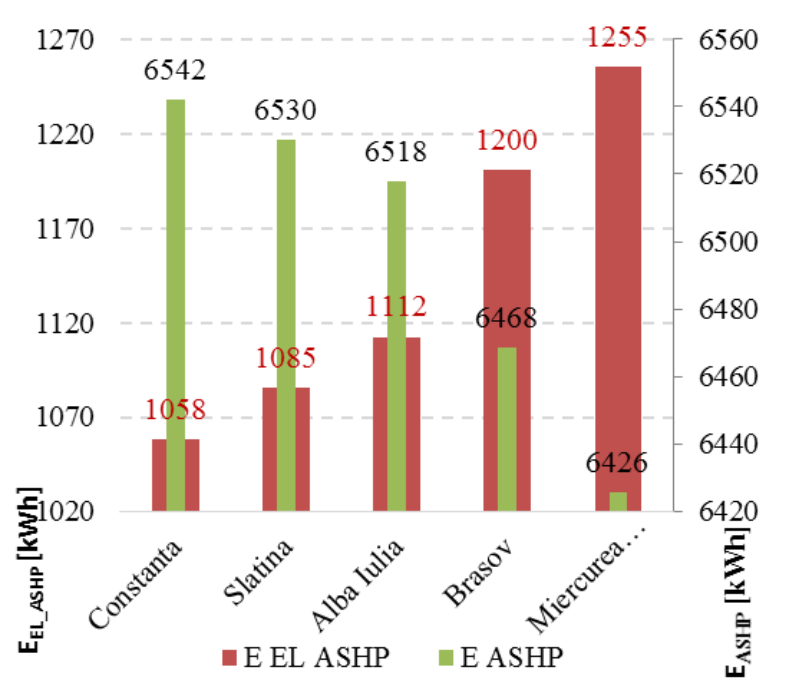

Fig. 9. Electrical energy consumption versus daily hot water energy delivered by ASHP

For the plotted values, in Figure 8, 0.6 isentropic efficiency is considered, $10^{\circ} \mathrm{C}$ and $55^{\circ} \mathrm{C}$ cold respectively set point water temperatures. Demanded water flow is for 4 persons with a flow equal $85 \mathrm{l} / \mathrm{day} /$ occupant. The simulation were done only for ASHP configuration, due to air temperatures obtained with Meteonorm database. Corresponding results are evaluated for 8760 days data, for entire representative year. For electrical factor over 0.24, it start a stabilization of renewable energy ratio. This value is used to next simulations.

Electrical energy consumption, in ASHP system, to deliver a delta temperature difference between cold and hot water equal $45^{\circ} \mathrm{C}$, with a 0.6 isentropic efficiency and electrical factor 0.24 , is represented together with delivered energy for heating of DHW demand over the year in Figure 9.

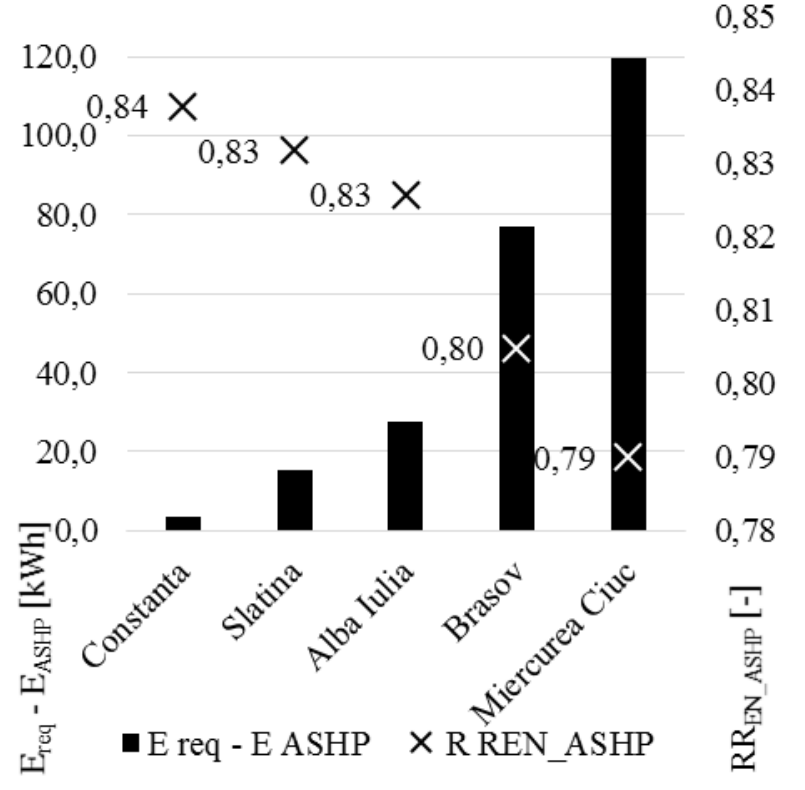

Fig. 10. Auxiliary energy required, $E_{\text {req }}-E_{A S H P}$, versus renewable energy ratio.

For the same values of different parameters, auxiliary energy together with renewable energy ratio are also important parameters to take into consideration for optimization of such system. In Figure 10 can be observed the variation of both indicators.

\section{Conclusions}

Air and water source heat pumps are generally the most used configuration for water heating systems. Both are based on refrigerant state working conditions and system performances depends more on temperature differences between condenser and evaporator. This paper presented an optimization technique to use and a design consideration parameters.

Startng with Figure 3, and till Figure 7, different working and mechanical based parameters are evaluated. For $0.2 \mathrm{f}_{\mathrm{DHW}}$, with $10^{\circ} \mathrm{C}$ external temperature the heating required to heat-up the water for $\mathrm{DHW}$, is satisfied by the system. For $701 /$ day/occupant, $65^{\circ} \mathrm{C}$ set point water temperature and 0 . Isentropic efficiency, the system WSHP considered can deliver the entire heating power 
comparing ASHP, which cannot sustain neither one of the possible cold water temperature in a range of 5 to $20^{\circ} \mathrm{C}$ according Figure 4 . This behavior is normal, $f_{\mathrm{DHW}}$ for both systems being the same. First conclusion reveal the necessity of different electrical factors between types of configuration. Also, can be possible to satisfy the required energy, if the set-point temperature is decreased, for both configuration, according Figure 5. Figure 4 and Figure 5 reveal that for the same electrical factor, system configuration will provide more than required heating, for WSHP, when ASHP can deliver entire heating in some configuration, respectively when WSHP can deliver a part of required heating below certain parameters.

If isentropic efficiency together with external temperature are varied, exist configurations, for both systems, to satisfy the required heating. In Figure 6, for isentropc efficiency above 0.6 and external temperature over $-1^{\circ} \mathrm{C}$, both configuration can deliver the entire heating required for DHW,

When occupant water flow is varied, for $65^{\circ} \mathrm{C}$, Figure 7 show the minimal condition to satisfy, with both configuration, the required heating power. For external temperatures over $1^{\circ} \mathrm{C}$, can be delivered to $\mathrm{DHW}$ system the entire required heating.

From energetic point of view, the most important parameter, presented by this paper, electrical factor, in Figure 8 , the renewable energy ratio start stabilizing the value, over 0.24 from required heat demand. With this value in hand, for 5 cities from Romania, electrical energy and delivered energy from a ASHP is ploted in Figure 9. Regarding Miercurea Ciuc, a cold area city, the biggest electrical energy, $1255 \mathrm{kWh}$, is required to deliver the heating demand over entire year. From Figure 10 we can note that in Constanta, the hottest area of Romania, the renewable energy ratio is 0.84 , with a very low auxiliary source energy demand, when in Miercurea Ciuc, only 0.79 renewable energy ratio is obtained, with auxiliary source energy demand over $120 \mathrm{kWh}$.

\section{References}

1. F. Iordache, M. Talpiga, Equipment and thermal systems. Energetic and functional evaluation methods, 99-110 (2017)

2. F. Iordache, M. Talpiga, Systems for the use of renewable sources. Methods of energy assessment and sizing , 49-65 (2018)

3. M.F. Talpiga, E. Mandric, F. Iordache, Nearly Zero Energy Communities (2018)

4. J.T. Vera, T. Laukkanen, K. Siren, Energy Build. 74, 78-90 (2014)

5. REN21, Global Status Report, (2018)

6. D. Haillot, E. Franquet, S. Gibout, J.P. Bedecarrats, Appl. Energy 109, 470-475 (2013)

7. J. Deng, S. Furbo, W. Kong, J. Fan, Energy Build. 172, 10-21 (2018)
8. T. Kousksou, P. Bruel, G. Cherreau, V. Leoussoff, T. El Rhafiki, Sol. Energy Procedia 85, 2033-2040 (2011)

9. E. Talmatsky, A. Kribus, Sol. Energy 82, 861-869 (2008)

10. M. Fumagalli, A. Sivieri, M. Aprile, M. Motta, M. Zanchi, Renewable Energy 110, 115-125 (2017)

11. T. Kim, B. Choi, Y.S. Han, K.H. Do, Energy Convers. Manage. 172, 472-484 (2018)

12. W. Wu, T. You, B. Wang, W. Shi, X. Li, Appl. Energy 12, 113-122 (2014)

13. C.M. Keinath, S. Garimella, Int. J. Refrig 88, 151171 (2018)

14. D. Zou, X. Ma, X. Liu, P. Zheng, B. Cai, J. Huang, J. Guo, M. Liu, Appl. Energy 206, 784-792 (2017)

15. J. Wu, Y. Feng, C. Liu, H. Li, Appl. Therm. Eng. 142, 644-655 (2018)

16. Z. Wang, F. Wang, Z. Ma, C. Li, Y. Xu, Energy Procedia 121, 134-141 (2017)

17. D. Qv, L. Ni, Y. Yao, W. Hu, Renewable Energy 84, 46-55 (2015)

18. Z. Wang, M. Song, F. Wang, Z. Ma, Q. Lin, Energy Build. 179, 200-212 (2018)

19. Y. Chung, J.W. Yoo, G.T. Kim, M.S. Kim, Appl. Therm. Eng. 147, 410-420 (2019)

20. Y. Lv, P. Si, X. Rong, J. Yan, Energy Procedia 145, 592-597 (2018)

21. Z. Kang, X. Zhou, Y. Zhao, R. Wang, X. Wang, Procedia Engneering 205, 1691-1697 (2017)

22. E. Fuentes, L. Arce, J. Salom, Renewable Sustainable Energy Rev. 81, 1530-1547 (2018)

23. L. Gavalda, M.Garcia-Nunez, S. Quero, C. Gutierrez-Milla, M. Sabria, Water Res. 149, 460466 (2019)

24. H. Zhou, W. Zhou, J. Wu, Z. Zhou, S. Ding, Procedia Engineering 205, 1635-1641 (2017)

25. S. Zou, X. Xie, Appl. Therm. Eng. 112, 201-207 (2017)

26. M.K. Loffler, Int. J. Refrig 54, 142-150 (2015)

27. M.N. Hamsani, T.G. Walmsley, P.Y. Liew, S.R.W. Alwi, Energy 153, 100-112 (2018)

28. Z. Liu, L. Zhao, X. Zhao, H. Li, Appl. Energy 97, 869-875 (2012)

29. C.I. Tuan, Y.L. Yeh, C.J. Chen, T.C. Chen, J. Taiwan Inst. Chem. Eng. 43, 226-234 (2012)

30. J. Koci, V. Koci, J. Madera, R. Cerny, Renewable Sustainable Energy Rev. 100, 22-32 (2019) 